\section{Control of liver cell fate decision by a gradient of TGF $\beta$ signaling modulated by Onecut transcription factors}

\author{
Frédéric Clotman, ${ }^{1}$ Patrick Jacquemin, ${ }^{1}$ \\ Nicolas Plumb-Rudewiez, ${ }^{1}$ \\ Christophe E. Pierreux, ${ }^{1}$ \\ Patrick Van der Smissen, ${ }^{2}$ Harry C. Dietz, ${ }^{3}$ \\ Pierre J. Courtoy, ${ }^{2}$ Guy G. Rousseau, ${ }^{1}$ and \\ Frédéric P. Lemaigre ${ }^{1,4}$
}

\begin{abstract}
${ }^{1}$ Hormone and Metabolic Research Unit, ${ }^{2}$ Cell Biology Unit, Institute of Cellular Pathology and Université catholique de Louvain, 1200 Brussels, Belgium; ${ }^{3}$ Institute of Genetic Medicine, Johns Hopkins University School of Medicine, Baltimore, Maryland 21205, USA
\end{abstract}

During liver development, hepatocytes and biliary cells differentiate from common progenitors called hepatoblasts. The factors that control hepatoblast fate decision are unknown. Here we report that a gradient of activin/ TGF $\beta$ signaling controls hepatoblast differentiation. High activin/TGFß signaling is required near the portal vein for differentiation of biliary cells. The Onecut transcription factors HNF-6 and OC-2 inhibit activin/TGF $\beta$ signaling in the parenchyma, and this allows normal hepatocyte differentiation. In the absence of Onecut factors, the shape of the activin/TGF $\beta$ gradient is perturbed and the hepatoblasts differentiate into hybrid cells that display characteristics of both hepatocytes and biliary cells. Thus, a gradient of activin/TGF $\beta$ signaling modulated by Onecut factors is required to segregate the hepatocytic and the biliary lineages.

Supplemental material is available at http://www.genesdev.org.

Received February 14, 2005; revised version accepted June 14, 2005.

During liver development, bipotent progenitors called hepatoblasts differentiate into hepatocytes or into biliary cells (Germain et al. 1988). The hepatoblasts located in the liver parenchyma give rise to the hepatocytes. In contrast, biliary differentiation is induced exclusively in hepatoblasts located at the interface between the mesenchyme surrounding the portal vein and the liver parenchyma (for review, see Lemaigre 2003). Because of this specific location, it has been hypothesized that a signal arising from the portal mesenchyme or from the endothelium of the portal vein induces biliary differentiation (Shiojiri 1984; Van Eyken et al. 1988; Shah and

[Keywords: Hepatoblasts; hepatic differentiation; activin/TGF $\beta$ signaling gradient; Onecut transcription factors; liver development]

${ }^{4}$ Corresponding author.

E-MAIL lemaigre@horm.ucl.ac.be; FAX 32-2-764-75-07.

Article and publication are at http://www.genesdev.org/cgi/doi/10.1101/ gad.340305.
Gerber 1990; Shiojiri and Koike 1997). The Notch pathway was suspected to mediate this signal (Li et al. 1997; Oda et al. 1997; McCright et al. 2002). However, recent in vivo data rather support a role for Notch in bile duct morphogenesis (Kodama et al. 2004). Other candidates include the TGF $\beta$ and the HGF pathways. Indeed, TGF $\beta$ affects differentiation of cultured hepatic cells (Isfort et al. 1997; Spagnoli et al. 2000), and the activin/TGF $\beta$ signaling mediators Smad2 and Smad3 cooperate with HGF signaling to control the hepatic architecture (Weinstein et al. 2001). However, the mechanisms that determine whether hepatoblasts differentiate into hepatocytes or into biliary cells remain unknown.

Our previous work on mice deficient in the transcription factor Hepatocyte Nuclear Factor-6 (HNF-6)/Onecut-1 (OC-1) showed that this factor is involved in biliary cell differentiation and is required for bile duct morphogenesis (Clotman et al. 2002). OC-2, another Onecut factor, is, like HNF-6, expressed in hepatoblasts, in hepatocytes, and in the biliary cells (Jacquemin et al. 2003; Supplementary Fig. S1A). The sequence conservation between HNF-6 and OC-2 suggests that they control the same target genes (Jacquemin et al. 1999), and may therefore exert redundant functions.

\section{Results and Discussion}

HNF-6 and OC-2 are required to segregate the hepatocytic and the biliary lineages during hepatoblast differentiation

To examine if HNF-6 and OC- 2 exert redundant functions in liver development, sections from knockout fetuses deficient in HNF-6 $\left(\mathrm{Hnf6}^{-1-}\right)$, or in OC-2 $\left(\mathrm{Oc}^{-1-}\right)$ (Supplementary Fig. S2) or in both factors ( $\mathrm{Hnf} 6 / \mathrm{Oc}^{-{ }^{-}}$) collected at embryonic day 15.5 (E15.5) were analyzed by immunofluorescence (Fig. 1A). At that stage, the liver contains epithelial cells (hepatoblasts, hepatocytes, and biliary cells; E-cadherin labeling) (see also Supplementary Fig. S1B) and hematopoietic cells (mainly erythroblasts; Ter119 labeling). In wild-type livers, the biliary cells were organized as typical ductal plates around the branches of the portal vein. They expressed biliary-specific cytokeratins (CK labeling), produced a basal lamina on the portal side of the ductal plate (laminin labeling) (arrows in Fig. 1A), and did not express HNF-4a. The hepatoblasts and hepatocytes (both labeled by HNF- $4 \alpha$ ) were organized in the liver parenchyma as cords devoid of basal lamina and interspersed with hematopoietic cells (Fig. 1A). In $\mathrm{Hnf6}^{-/-}$fetuses, biliary cysts were observed in the vicinity of the portal vein (asterisks in Fig. 1A), as described earlier (Clotman et al. 2002), whereas premature dilations were observed within the ductal plates in $\mathrm{Oc2}^{-1-}$ fetuses (arrowheads in Fig. 1A). Data collected at later stages indicated that, like HNF-6, OC-2 is required for bile duct morphogenesis (Supplementary Fig. S3A). The cord-like organization of the epithelial cells in the parenchyma was normal in the single $\mathrm{HnfG}^{-/-}$or $\mathrm{Oc2^{-/- }}$ knockout fetuses (Fig. 1A). In contrast, it was severely perturbed in double Hnfo/ $\mathrm{Oc2}^{-/-}$knockout livers, since the epithelial cells formed clusters surrounded by hematopoietic cells (Fig. 1A,B). The cells in these clusters retained expression of epithe- 
Clotman et al.

A
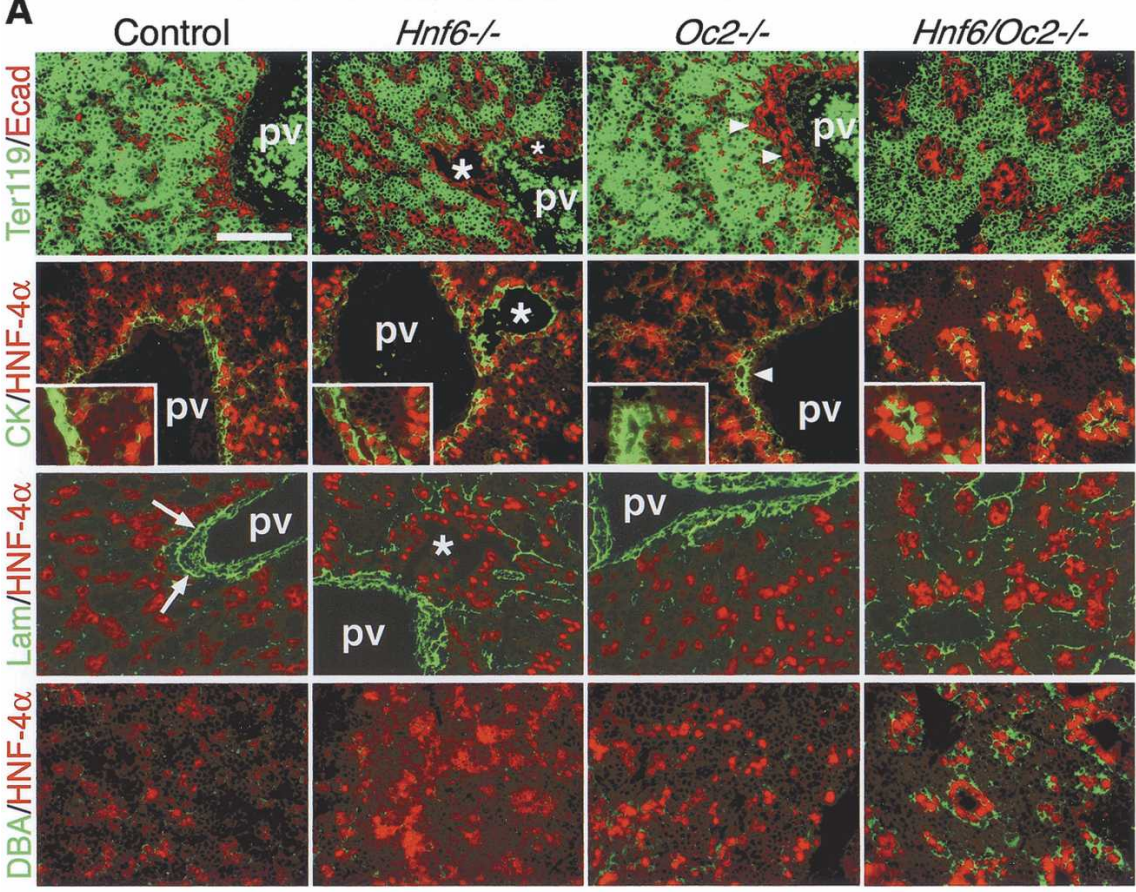

B

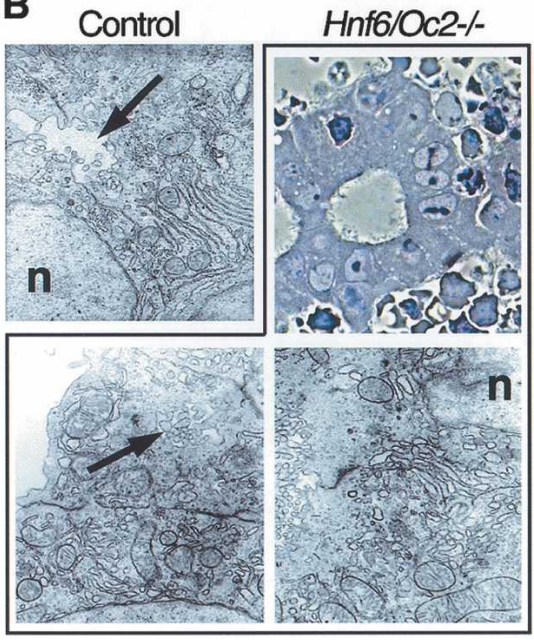

C

\begin{tabular}{c|c|c|c|c|}
\cline { 2 - 4 } Hnf6 & $+/+$ & $=/$ & $+/+$ & $-/=$ \\
Oc2 & $+/+$ & $+/+$ & $-/-$ & $-/-$ \\
\cline { 2 - 5 } cpsl & 21.6 & 24.1 & 13.3 & 14.7 \\
\pm & \pm & \pm & \pm \\
& 3.5 & 6.8 & 2.8 & 2.8 \\
& & & & \\
gys2 & 38.5 & 27.7 & 35.9 & 38.8 \\
\pm & \pm & \pm & \pm \\
& 8.0 & 9.1 & 11.2 & 4.1 \\
ggt4 & &
\end{tabular}

Figure 1. HNF-6 and OC-2 are required to segregate the hepatocytic and biliary lineages. (A) In the absence of HNF-6 and OC-2, the hepatoblasts give rise to hybrid cells coexpressing hepatoblast/hepatocyte and biliary markers. Markers of epithelial cells (Ecad, E-cadherin), erythroid cells (Ter119), hepatoblasts and hepatocytes (HNF-4 $\alpha$ ), or biliary cells ([CK] cytokeratin; [Lam] laminin; [DBA] Dolichos biflorus agglutinin) were detected on E15.5 liver sections. (Insets) Higher magnifications of CK/HNF-4 $\alpha$ labelings. (pv) Portal vein; (arrows) biliary basal lamina; (asterisks) biliary cysts in $H n f 6^{-/-}$livers; (arrowheads) dilations within the ductal plate in Oc2 ${ }^{-/-}$livers. Bar, $100 \mu \mathrm{m}$. (B) The hybrid cells in $\mathrm{Hnf} 6 / \mathrm{Oc}^{-/-}$livers have morphological characteristics of hepatocytes. For $\mathrm{Hnf6} / \mathrm{Oc2^{-/- }}$ liver at E15.5, a semithin section (upper right) shows hybrid cells surrounded by hematopoietic cells; in hybrid cells, a well-developed rough endoplasmic reticulum (lower right), abundant mitochondria, and a bile canaliculus (lower left, arrow) were observed by electron microscopy. (n) Nucleus; (arrows) bile canaliculi. (C) The hepatocyte markers carbamoyl phosphate synthase I (cpsI) and glycogen synthase 2 (gys2) are expressed in Onecut knockout livers, as shown by real-time RT-PCR quantification, [(mRNA copy number)/( $\beta$-actin mRNA copy number) $\times 10^{3}$ (mean \pm SEM). The expression of the biliary marker $\gamma$-glutamyl transpeptidase 4 (ggt4) is increased in Onecut knockout livers, as shown by semiquantitative RT-PCR with TATA-binding protein gene $(t b p)$ as control.

lial markers (Fig. 1A; Supplementary Fig. S4), indicating that their epithelial character was maintained. Surprisingly, these clustered cells coexpressed CK and HNF$4 \alpha$ (inset in Fig. 1A) and were surrounded by a basal lamina. They were also stained with Dolichos biflorus agglutinin (DBA labeling) (Fig. 1A), which normally only labels the biliary cells (Shiojiri and Katayama 1988).
Thus, in the combined absence of HNF-6 and OC-2, all hepatoblasts differentiated into hybrid cells coexpressing hepatoblast/hepatocyte and biliary markers. Such hybrid cells were also observed in the vicinity of the portal vein in the single $\mathrm{Hnf6}^{-/-}$knockout livers but not in $\mathrm{Oc}^{-/-}$livers (insets in Fig. 1A; Supplementary Fig. S3B). 
To evaluate if the hybrid cells displayed characteristics of differentiated hepatocytes, we studied their morphology in $\mathrm{Hnf} 6 / \mathrm{Oc} 2^{-\digamma-}$ livers by electron microscopy (Fig. 1B). The hybrid cells were polygonal with a large nucleus, a well-developed rough endoplasmic reticulum, and numerous mitochondria and bile canaliculi (arrows in Fig. 1B), all features that are typical of differentiated hepatocytes (Fig. 1B). This was further supported by the expression in $\mathrm{Hnf6} / \mathrm{Oc}^{-/-}$livers of the hepatocyte differentiation markers carbamoylphosphate synthase I (cpsI) and glycogen synthase 2 (gys2), although cpsI expression levels were reduced in $\mathrm{Oc}^{-/-}$and in $\mathrm{Hnf6/}$ $\mathrm{Oc2}^{-/-}$livers as compared to wild-type liver (Fig. 1C). In contrast, the expression of the biliary differentiation marker $\gamma$-glutamyl transpeptidase 4 (ggt4) was strongly increased (Fig. 1C), consistent with the increased expression of other biliary markers as detected by immunofluorescence. Taken together, the data indicate that in the combined absence of HNF-6 and OC-2, the hepatocytic and the biliary differentiation programs are activated in the same cells. Thus, HNF- 6 and OC- 2 are required to segregate the hepatocytic and biliary lineages during hepatoblast differentiation.

HNF-6 and OC-2 control the shape of an activin/TGFß signaling gradient in fetal liver

To address the mechanism of action of the Onecut factors, we built upon our earlier finding that cells isolated from $\mathrm{Hnf6}^{-/-}$livers display increased TGF $\beta$ signaling associated with increased expression of the TGF $\beta$ receptor type II (tbrII) (Plumb-Rudewiez et al. 2004). We found that at E12.5, namely, just before the onset of the abnormal phenotype (Supplementary Fig. S3B), tbrII expression was increased in $\mathrm{Hnf6/Oc2^{-/- }}$ livers like in $\mathrm{Hnf6}^{-/-}$ livers, but was normal in $O c 2^{-/-}$livers (Fig. 2A). Likewise, we assessed the expression of other components of the activin/TGF $\beta$ pathway and found that the expression level of the potential TGF $\beta$ antagonist $\alpha 2$-macroglobulin (Arandjelovic et al. 2003) and of the activin antagonist follistatin (Massague 2000) was reduced in $\mathrm{Hnf6}^{-/-}$, in $\mathrm{Oc2}^{-/-}$, and in $\mathrm{Hnf6} / \mathrm{Oc2}^{-/-}$livers (Fig. 2A). These changes suggested that activin/TGF $\beta$ signaling is increased in the absence of Onecut factors. To functionally evaluate activin/TGF $\beta$ signaling in vivo, we crossbred the Onecut knockout mice with CAGA12/GFP transgenic mice harboring an activin/TGFß-responsive GFP gene (Neptune et al. 2003). In control livers at E12.5, GFP activity was high in the vicinity of the portal vein, where hepatoblasts will differentiate into biliary cells, and lower in the rest of the parenchyma, where hepatoblasts will differentiate into hepatocytes (Fig. $2 \mathrm{~B}, \mathrm{C})$. This revealed the existence of a gradient of activin/TGF $\beta$ signaling. Activin/TGF $\beta$ signaling was moderately increased in the single knockouts and strongly increased in $\mathrm{Hnf6/Oc2^{-/ }}$ livers. In the double Hnf6/ $\mathrm{Oc} 2^{-/-}$knockouts, high signaling extended farther away from the portal vein than in control fetuses (Fig. 2B,C). We concluded that there is a gradient of activin/TGF $\beta$ signaling in developing liver and that the shape of this gradient is controlled by HNF-6 and OC-2. In addition, the spatial correlation between high activin/TGF $\beta$ signaling and differentiation of hepatoblasts into biliary cells suggested that this signaling pathway controls biliary differentiation.
A

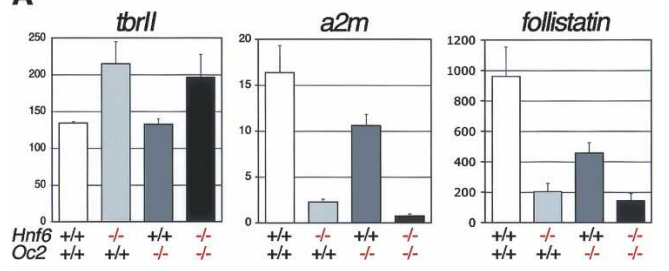

B Control CAGAVGFP

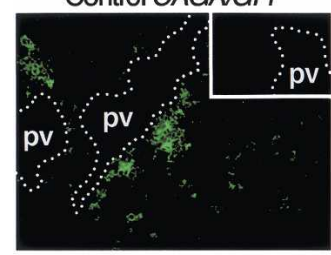

Hnf6-- CAGAGFP
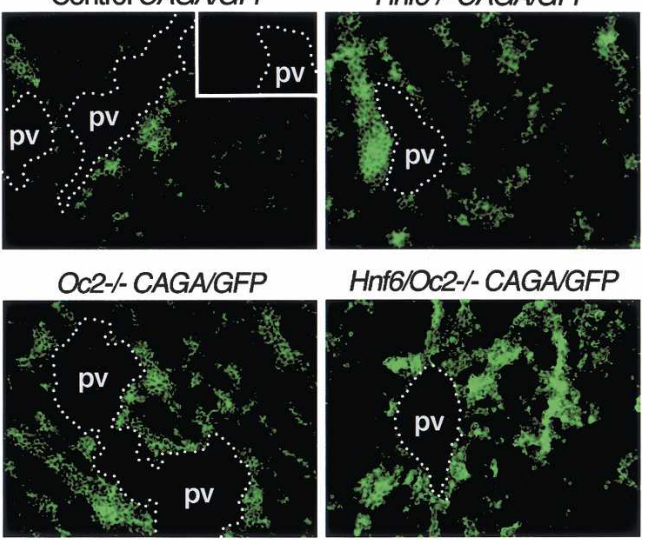

Hnf6/Oc2- $/$ - CAGA/GFP

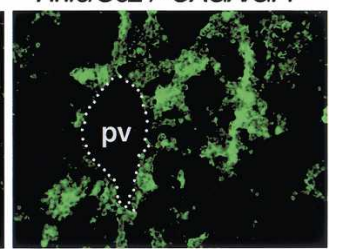

C

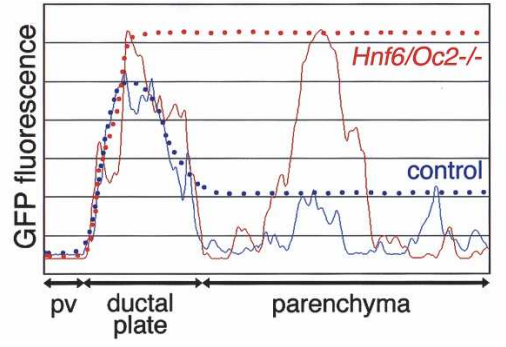

Figure 2. HNF-6 and OC-2 inhibit activin/TGF $\beta$ signaling. $(A)$ HNF- 6 and OC- 2 control the expression of components of the activin/TGF $\beta$ signaling pathway. Real-time RT-PCR for TGF $\beta$-receptor type II (tbrII), $\alpha 2$-macroglobulin $(a 2 \mathrm{~m})$ or follistatin at E12.5, expressed as [(mRNA copy number $) /(\beta$-actin mRNA copy number) $] \times 10^{3}($ mean \pm SEM).$(B, C)$ Activin/TGF $\beta$ signaling occurs as a gradient in E12.5 liver and is increased in the absence of Onecut factors. (B) $\mathrm{Hnf6}^{+/-} \mathrm{Oc2}^{+/-}$mice were crossbred with transgenic mice harboring an activin/TGF $\beta$ reporter consisting of 12 Smad-binding sites upstream of EGFP (CAGA12/GFP). The dotted lines delineate the branches of the portal vein. The inset shows background fluorescence of a section from a nontransgenic liver. (pv) Portal vein. Bar, $100 \mu \mathrm{m} .(C)$ GFP fluorescence profile from the portal vein to the parenchyma in control CAGA12/GFP liver (blue tracing) and in Hnf6/Oc2 ${ }^{-/-}$CAGA12/GFP liver (red tracing). In the parenchyma, basal fluorescence levels correspond to hematopoietic cells, and higher levels to epithelial cells. The dotted lines show the shape of GFP fluorescence gradients in the epithelial cells. "Ductal plate" refers to the area where the ductal plate will form. (pv) Portal vein.

\section{Activin/TGFß signaling is required for biliary differentiation}

To investigate whether activin or TGF $\beta$ can induce biliary differentiation, we developed an ex vivo culture model of E12.5 liver explants. Under basal conditions, hepatocyte differentiation occurred spontaneously in the explants as detected by cpsI and gys 2 expression, but biliary differentiation did not proceed. However, incubation of the explants with TGF $\beta$ or activins stimulated expression of the biliary markers ggt4 and integrin $\beta 4$ 
(ib4) (Fig. 3A). Furthermore, beads soaked in TGF $\beta$ or activin $\mathrm{B}$ and then implanted into the explants induced a local and gradient-wise expression of biliary-specific cytokeratins (Fig. 3B). We concluded that activin/TGF $\beta$ signaling can induce biliary differentiation.

To test if TGF $\beta$ is required in vivo for biliary differentiation, pregnant wild-type mice were injected intraperitoneally at E10.5 with anti-TGF $\beta$ neutralizing antibodies. Such antibodies were previously shown to inhibit TGF $\beta$ signaling in developing fetuses (Neptune et al. 2003). Administration of the anti-TGF $\beta$ antibodies inhibited biliary differentiation in the fetal livers, as evidenced at E14.5 by the reduction in the amount of biliary-specific cytokeratin-positive cells around the portal vein, and by the absence of biliary basal lamina (Fig. 3C). This inhibition did not result from alterations of the portal vein endothelium, since the expression of the endothelial marker PECAM was unaffected in treated livers (Supplementary Fig. S5). These data demonstrate that TGF $\beta$ signaling is required for differentiation of hepatoblasts into biliary cells.

The present work shows that a gradient of activin/
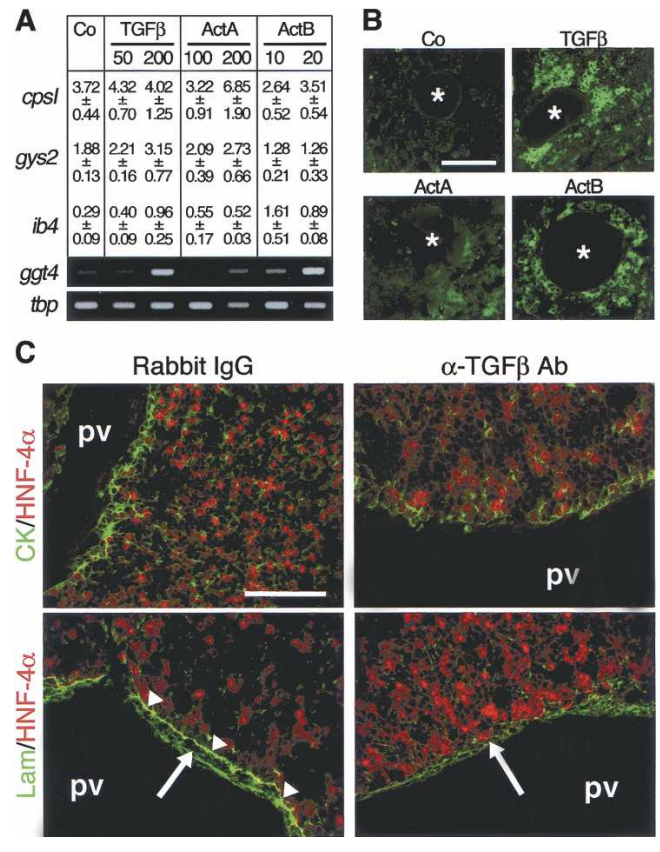

Figure 3. Activin/TGF $\beta$ signaling induces biliary differentiation. (A) Activin and TGF $\beta$ can stimulate biliary differentiation in fetal liver explants. E12.5 explants were cultured in the absence (Co) or in the presence of recombinant TGF $\beta-1$ (TGF $\beta$ ), activin A (ActA), or activin B (ActB) (in picograms per milliliter). Real-time RT-PCR quantification was performed for the biliary marker integrin $\beta 4$ (ib4) or the hepatocyte markers cpsI and gys2, [(mRNA copy number $) /(\beta$ actin mRNA copy number) $] \times 10^{3}$ (mean \pm SEM). The expression of the biliary marker ggt 4 was evaluated by semiquantitative RT-PCR, with $t b p$ as control. (B) A local source of activin or TGF $\beta$ induces a gradient-wise expression of biliary cytokeratins in fetal liver explants. Beads $\left({ }^{*}\right)$ soaked into TGF $\beta-1$, activin A, or activin B were implanted into E12.5 liver explants. After culture, sections were labeled for biliary cytokeratins. $(C)$ TGF $\beta$ signaling is required for biliary differentiation. Wild-type pregnant mice were injected at E10.5 with anti-TGF $\beta$-neutralizing antibodies or rabbit IgG as control. Sections collected at E14.5 were labeled for HNF- $4 \alpha$ and biliary cytokeratins (CK) or laminin (Lam). (Arrowheads) Biliary basal lamina; (arrows) laminin produced by the mesenchyme surrounding the portal vein; (pv) portal vein. Bars, $100 \mu \mathrm{m}$.
TGF $\beta$ signaling, shaped by Onecut transcription factors, controls cell lineage decision during liver development. Such a gradient is expected to result from the integration of local concentrations of active ligands (Annes et al. 2003), antagonists, and receptors, with the expression levels of the activin/TGF $\beta$ signaling mediators (Massague 2000). The expression pattern of some components of the activin/TGF $\beta$ pathway has been described in fetal liver (Pelton et al. 1990; Millan et al. 1991; Schmid et al. 1991; Feijen et al. 1994; Lorent et al. 1995; Verschueren et al. 1995; de Sousa Lopes et al. 2003), but these data are not sufficient to explain how the gradient is formed. We found that a perturbation of the TGF $\beta$ gradient is associated with perturbed expression of tbrII, follistatin, and a2-macroglobulin in the single $\mathrm{Hnf6}^{-/-}$or $\mathrm{Oc}^{-/-}$knockouts and in double $\mathrm{Hnf} 6 / \mathrm{Oc} 2$ knockouts. The sum of these defects in each single or double knockout correlates with the intensity of gradient perturbation. This suggests that Onecut factors control the shape of the gradient, at least in part by modulating the expression of

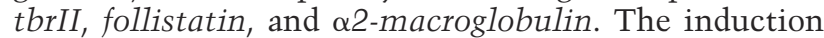
of the biliary differentiation program in hepatoblasts located at a distance from the portal mesenchyme in the $\mathrm{Hnf6} / \mathrm{Oc}^{-/-}$livers indicates that a direct interaction between hepatoblasts and the portal mesenchyme, which is thought to be mediated by the Notch pathway (Li et al. 1997; Oda et al. 1997; McCright et al. 2002), is not required to induce biliary differentiation. The Notch pathway may act in parallel to or downstream from the activin/TGF $\beta$ signaling to support biliary differentiation induced by activin and TGF $\beta$, or, as suggested by Tanimizu and Miyajima (2004), to repress the hepatocytic differentiation program in biliary cells.

The developmental mechanisms uncovered here have implications for the identification of growth factors and transcription factors required to generate differentiated cells for cell therapy of liver diseases. In addition, they may help identify the etiology of human congenital biliary diseases, such as biliary atresia. These diseases are associated with developmental anomalies similar to the ductal plate malformations found in $\mathrm{Hnf6}^{-/-}$or $\mathrm{Oc}^{-/-}$ knockout livers (Desmet 1992; Perlmutter and Shepherd 2002). Therefore, we propose that the Onecut factors and TGF $\beta$ signaling components are new candidates to study the etiopathogeny of congenital biliary diseases.

\section{Materials and methods}

\section{Generation of Oc2 knockout mice}

A targeting construct was designed to generate an Oc2-null allele, and $\mathrm{Oc}^{-/-}$mice were obtained as described in Supplementary Fig. S2.

\section{Immunolabelings}

Tissues were frozen in liquid nitrogen-cooled isopentane. Cryosections (5 $\mu \mathrm{m}$ for liver, $10 \mu \mathrm{m}$ for explants) were post-fixed for $10 \mathrm{~min}$ in acetone at $4^{\circ} \mathrm{C}$. Primary antibodies were mouse anti-human E-cadherin (PharMingen), rat anti-mouse TER-119 (PharMingen), rabbit anti-human keratin that labels the biliary cells (Van Eyken et al. 1988; Clotman et al. 2002) (DAKO), goat anti-human HNF-4 $\alpha$ (Santa Cruz), rabbit anti-mouse laminin (Sigma), and rat anti-mouse PECAM-1 (PharMingen). Secondary antibodies were donkey anti-goat/AlexaFluor 594 or anti-rat/AlexaFluor 594 (Molecular Probes), or biotinylated sheep anti-rabbit or anti-mouse antibody (Chemicon) followed by streptavidin-AlexaFluor 488 (Molecular Probes). Biotinylated D. biflorus agglutinin (Vector) was detected with streptavidin-AlexaFluor 488. For OC-2 staining, livers were fixed in $4 \%$ paraformaldehyde at $4{ }^{\circ} \mathrm{C}$ and were frozen in gelatin/sucrose solution prior to sectioning at $10 \mu \mathrm{m}$. Rat anti-OC-2 antibodies were raised against the $\mathrm{N}$-terminal moiety of mouse OC-2 (amino acids 36-311) 
fused downstream from glutathione-S-transferase (GST). Primary antibodies were detected by immunoperoxidase activity using biotinylated sheep anti-rat immunoglobulins $\mathrm{G}$ (Chemicon) followed by a streptavidin-peroxydase conjugate (Chemicon) and DAB+ (Dako).

Semithin sections and transmission electron microscopy

Livers were fixed in $4 \%$ formaldehyde at $4^{\circ} \mathrm{C}$ for $2 \mathrm{~h}$, then cut in small blocks and further fixed in $4 \%$ formaldehyde/ $1 \%$ glutaraldehyde at $4{ }^{\circ} \mathrm{C}$ for $2.5 \mathrm{~h}$. They were post-fixed in reduced osmium at $4^{\circ} \mathrm{C}$ for $1 \mathrm{~h}$, stained in block with $2 \%$ uranyl acetate, dehydrated, and embedded in Spurr. Sections were observed in a CM12 transmission electron microscope at $80 \mathrm{kV}$.

\section{RT-PCR and real-time RT-PCR}

Total RNA was prepared using Tripure Isolation Reagent (Roche). Reverse transcription (Life Technologies reagents) and PCR (Promega reagents) were performed as described (Plumb-Rudewiez et al. 2004). Realtime PCR was performed with SYBR Green Core Reagents (Perkin Elmer) on a MyiQ cycler (Bio-Rad). Absolute copy number for each mRNA was normalized to the absolute $\beta$-actin mRNA copy number. PCR primer sequences are available upon request.

\section{CAGA12/GFP transgenic mice}

Heterozygous CAGA12/GFP mice (Neptune et al. 2003) were crossbred with $\mathrm{Hnf6}^{+/-} \mathrm{Oc2}^{+/-}$mice, and the progeny was genotyped by PCR. $\mathrm{Hnf6}^{+/-} \mathrm{Oc2}^{+/-} \mathrm{CAGA12/GFP}$ animals were then mated with $\mathrm{Hnf6}^{+/-}$ $\mathrm{Oc} 2^{+/-}$mice. All animals received humane care according to the criteria outlined in the Guide for the Care and Use of Laboratory Animals prepared by the National Academy of Sciences (USA) and published by the National Institutes of Health. Livers were collected at E12.5, fixed for 2 $\mathrm{h}$ in $1 \%$ paraformaldehyde, and frozen in $15 \%$ sucrose $/ 7.5 \%$ gelatin in PBS. Cryosections $(10 \mu \mathrm{m})$ were prepared and immediately observed for GFP fluorescence. GFP fluorescence was quantified with the Image software.

\section{Culture of liver explants on Teflon membranes}

Livers were collected at E12.5, and the four major lobes were cultured separately on Millicell-CM Culture Plate Inserts (Millipore) in standard 24-well plates containing $300 \mu \mathrm{L}$ of RPMI 1640 medium (Invitrogen) supplemented with $10 \%$ fetal calf serum, $50 \mathrm{ng} / \mathrm{mL}$ EGF, $30 \mathrm{ng} / \mathrm{mL}$ IGFII, $10 \mathrm{mg} / \mathrm{mL}$ insulin, Fungizone, and antibiotics. No medium was added on top of the filter to allow growth at the air/medium interface. Medium was changed every other day. Recombinant TGF- $\beta 1$, activin A, and activin B were from R\&D Systems. Affi-Gel Blue Gel beads (Bio-Rad) were washed in PBS and soaked overnight in TGF- $\beta 1(0.4 \mu \mathrm{g} / \mathrm{mL}$ ), activin A (up to $15 \mu \mathrm{g} / \mathrm{mL})$, or activin B $(2 \mu \mathrm{g} / \mathrm{mL})$. Control beads were soaked in PBS. They were then implanted with tungsten needles in liver explants (one bead per explant) immediately after dissection, and the explants were cultured for $6 \mathrm{~d}$.

\section{Anti-TGFß neutralizing antibodies}

Wild-type pregnant mice at E10.5 were injected i.p. with rabbit polyclonal pan-specific TGF- $\beta$ neutralizing antibody (R\&D Systems; $12 \mathrm{mg} /$ $\mathrm{kg}$ ) in a volume of $500 \mu \mathrm{L}$. This antibody was previously shown to inhibit TGFß signaling in vitro and in vivo (Tomita et al. 1998; Yamamoto et al. 1999), as well as in developing fetuses (Neptune et al. 2003). Control pregnant mice were injected similarly with irrelevant rabbit IgG (R\&D Systems; $12 \mathrm{mg} / \mathrm{kg}$ ). Fetal livers were collected at E14.5.

\section{Acknowledgments}

We thank Marie-Agnès Gueuning, Jean-François Cornut, Sabine Cordi, and Thanh Lac for technical assistance; Didier Vertommen for help in the purification of the OC-2/GST fusion protein; Kerstin Johansson for technical advice regarding detection of GFP fluorescence on sections; members of the HORM unit for discussions; and René Rezsohazy for comments on the manuscript. This work was supported by the Howard Hughes Medical Institute, and by grants from the Human Frontier Science Program, the Belgian State Program on Interuniversity Poles of Attraction, the French Community of Belgium, the Belgian Fund for Scientific Medical Research, and the NIH (AR41135 and AR049698). P.J. is Research Associate of the National Fund for Scientific Research (Belgium). N.P.R. holds a fellowship from Télévie.

\section{References}

Annes, J.P., Munger, J.S., and Rifkin, D.B. 2003. Making sense of latent TGF $\beta$ activation. J. Cell Sci. 116: 217-224.

Arandjelovic, S., Freed, T.A., and Gonias, S.L. 2003. Growth factor-binding sequence in human $\alpha 2$-macroglobulin targets the receptor-binding site in transforming growth factor- $\beta$. Biochemistry 42: 6121-6127.

Clotman, F., Lannoy, V.J., Reber, M., Cereghini, S., Cassiman, D., Jacquemin, P., Roskams, T., Rousseau, G.G., and Lemaigre, F.P. 2002. The onecut transcription factor Hnf6 is required for normal development of the biliary tract. Development 129: 1819-1828.

Desmet, V.J. 1992. Congenital diseases of intrahepatic bile ducts: Variations on the theme 'ductal plate malformation.' Hepatology 16: 1069-1083.

de Sousa Lopes, S.M., Carvalho, R.L., van den Driesche, S., Goumans, M.J., ten Dijke, P., and Mummery, C.L. 2003. Distribution of phosphorylated Smad2 identifies target tissues of TGF $\beta$ ligands in mouse development. Gene Expr. Patterns 3: 355-360.

Feijen, A., Goumans, M.J., and van den Eijnden-van Raaij, A.J. 1994. Expression of activin subunits, activin receptors and follistatin in postimplantation mouse embryos suggests specific developmental functions for different activins. Development 120: 3621-3637.

Germain, L., Blouin, M.J., and Marceau, N. 1988. Biliary epithelial and hepatocytic cell lineage relationships in embryonic rat liver as determined by the differential expression of cytokeratins, $\alpha$-fetoprotein, albumin, and cell surface-exposed components. Cancer Res. 48: 4909-4918.

Isfort, R.J., Cody, D.B., Stuard, S.B., Randall, C.J., Miller, C., Ridder, G.M., Doersen, C.J., Richards, W.G., Yoder, B.K., Wilkinson, J.E., et al. 1997. The combination of epidermal growth factor and transforming growth factor- $\beta$ induces novel phenotypic changes in mouse liver stem cell lines. J. Cell Sci. 110: 3117-3129.

Jacquemin, P., Lannoy, V.J., Rousseau, G.G., and Lemaigre, F.P. 1999. OC-2, a novel mammalian member of the ONECUT class of homeodomain transcription factors whose function in liver partially overlaps with that of hepatocyte nuclear factor-6. J. Biol. Chem. 274: 2665-2671.

Jacquemin, P., Pierreux, C.E., Fierens, S., van Eyll, J.M., Lemaigre, F.P., and Rousseau, G.G. 2003. Cloning and embryonic expression pattern of the mouse Onecut transcription factor OC-2. Gene Expr. Patterns 3: 639-644.

Kodama, Y., Hijikata, M., Kageyama, R., Shimotohno, K., and Chiba, T. 2004. The role of notch signaling in the development of intrahepatic bile ducts. Gastroenterology 127: 1775-1786.

Lemaigre, F.P. 2003. Development of the biliary tract. Mech. Dev. 120: $81-87$.

Li, L., Krantz, I.D., Deng, Y., Genin, A., Banta, A.B., Collins, C.C., Qi, M., Trask, B.J., Kuo, W.L., Cochran, J., et al. 1997. Alagille syndrome is caused by mutations in human Jagged1, which encodes a ligand for Notch1. Nat. Genet. 16: 243-251.

Lorent, K., Overbergh, L., Moechars, D., De Strooper, B., Van Leuven, F., and Van den Berghe, H. 1995. Expression in mouse embryos and in adult mouse brain of three members of the amyloid precursor protein family, of the $\alpha$-2-macroglobulin receptor/low density lipoprotein receptor-related protein and of its ligands apolipoprotein E, lipoprotein lipase, $\alpha$-2-macroglobulin and the 40,000 molecular weight receptorassociated protein. Neuroscience 65: 1009-1025.

Massague, J. 2000. How cells read TGF- $\beta$ signals. Nat. Rev. Mol. Cell. Biol. 1: 169-178.

McCright, B., Lozier, J., and Gridley, T. 2002. A mouse model of Alagille syndrome: Notch2 as a genetic modifier of Jag1 haploinsufficiency. Development 129: 1075-1082.

Millan, F.A., Denhez, F., Kondaiah, P., and Akhurst, R.J. 1991. Embryonic gene expression patterns of TGF $\beta 1, \beta 2$ and $\beta 3$ suggest different developmental functions in vivo. Development 111: 131-143.

Neptune, E.R., Frischmeyer, P.A., Arking, D.E., Myers, L., Bunton, T.E., Gayraud, B., Ramirez, F., Sakai, L.Y., and Dietz, H.C. 2003. Dysregulation of TGF- $\beta$ activation contributes to pathogenesis in Marfan syndrome. Nat. Genet. 33: 407-411.

Oda, T., Elkahloun, A.G., Pike, B.L., Okajima, K., Krantz, I.D., Genin, A., Piccoli, D.A., Meltzer, P.S., Spinner, N.B., Collins, F.S., et al. 1997. Mutations in the human Jagged1 gene are responsible for Alagille syndrome. Nat. Genet. 16: 235-242. 


\section{Clotman et al.}

Pelton, R.W., Dickinson, M.E., Moses, H.L., and Hogan, B.L. 1990. In situ hybridization analysis of TGF $\beta 3$ RNA expression during mouse development: Comparative studies with TGF $\beta 1$ and $\beta 2$. Development 110: 609-620.

Perlmutter, D.H. and Shepherd, R.W. 2002. Extrahepatic biliary atresia: A disease or a phenotype? Hepatology 35: 1297-1304.

Plumb-Rudewiez, N., Clotman, F., Strick-Marchand, H., Pierreux, C.E., Weiss, M.C., Rousseau, G.G., and Lemaigre, F.P. 2004. Transcription factor HNF-6/OC-1 inhibits the stimulation of the HNF-3 $\alpha /$ Foxal gene by TGF- $\beta$ in mouse liver. Hepatology 40: 1266-1274.

Schmid, P., Cox, D., Bilbe, G., Maier, R., and McMaster, G.K. 1991. Differential expression of TGF $\beta 1, \beta 2$ and $\beta 3$ genes during mouse embryogenesis. Development 111: 117-130.

Shah, K.D. and Gerber, M.A. 1990. Development of intrahepatic bile ducts in humans. Possible role of laminin. Arch. Pathol. Lab Med. 114: 597-600.

Shiojiri, N. 1984. The origin of intrahepatic bile duct cells in the mouse. J. Embryol. Exp. Morphol. 79: 25-39.

Shiojiri, N. and Katayama, H. 1988. Development of Dolichos biflorus agglutinin (DBA) binding sites in the bile duct of the embryonic mouse liver. Anat. Embryol. (Berl) 178: 15-20.

Shiojiri, N. and Koike, T. 1997. Differentiation of biliary epithelial cells from the mouse hepatic endodermal cells cultured in vitro. Tohoku J. Exp. Med. 181: 1-8.

Spagnoli, F.M., Cicchini, C., Tripodi, M., and Weiss, M.C. 2000. Inhibition of MMH (Met murine hepatocyte) cell differentiation by TGF $\beta$ is abrogated by pre-treatment with the heritable differentiation effector FGF1. J. Cell Sci. 113: 3639-3647.

Tanimizu, N. and Miyajima, A. 2004. Notch signaling controls hepatoblast differentiation by altering the expression of liver-enriched transcription factors. J. Cell Sci. 117: 3165-3174.

Tomita, H., Egashira, K., Ohara, Y., Takemoto, M., Koyanagi, M., Katoh, M., Yamamoto, H., Tamaki, K., Shimokawa, H., and Takeshita, A. 1998. Early induction of transforming growth factor- $\beta$ via angiotensin II type 1 receptors contributes to cardiac fibrosis induced by longterm blockade of nitric oxide synthesis in rats. Hypertension 32: 273279.

Van Eyken, P., Sciot, R., Callea, F., Van der Steen, K., Moerman, P., and Desmet, V.J. 1988. The development of the intrahepatic bile ducts in man: A keratin- immunohistochemical study. Hepatology 8: 15861595.

Verschueren, K., Dewulf, N., Goumans, M.J., Lonnoy, O., Feijen, A., Grimsby, S., Vandi Spiegle, K., ten Dijke, P., Moren, A., Vanscheeuwijck, P., et al. 1995. Expression of type I and type IB receptors for activin in midgestation mouse embryos suggests distinct functions in organogenesis. Mech. Dev. 52: 109-123.

Weinstein, M., Monga, S.P., Liu, Y., Brodie, S.G., Tang, Y., Li, C., Mishra, L., and Deng, C.X. 2001. Smad proteins and hepatocyte growth factor control parallel regulatory pathways that converge on $\beta 1$-integrin to promote normal liver development. Mol. Cell. Biol. 21: 5122-5131.

Yamamoto, T., Takagawa, S., Katayama, I., and Nishioka, K. 1999. Antisclerotic effect of transforming growth factor- $\beta$ antibody in a mouse model of bleomycin-induced scleroderma. Clin. Immunol. 92: 6-13. 


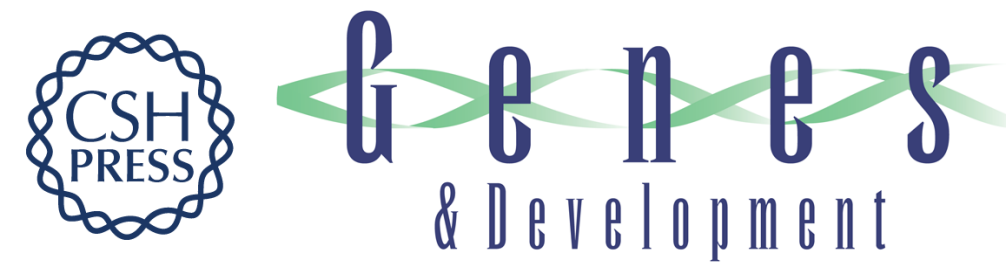

\section{Control of liver cell fate decision by a gradient of TGF $\beta$ signaling modulated by Onecut transcription factors}

Frédéric Clotman, Patrick Jacquemin, Nicolas Plumb-Rudewiez, et al.

Genes Dev. 2005, 19:

Access the most recent version at doi:10.1101/gad.340305

Supplemental
Material http://genesdev.cshlp.org/content/suppl/2005/08/16/19.16.1849.DC1

References This article cites 32 articles, 12 of which can be accessed free at:

http://genesdev.cshlp.org/content/19/16/1849.full.html\#ref-list-1

License

Email Alerting

Receive free email alerts when new articles cite this article - sign up in the box at the top

Service

right corner of the article or click here.

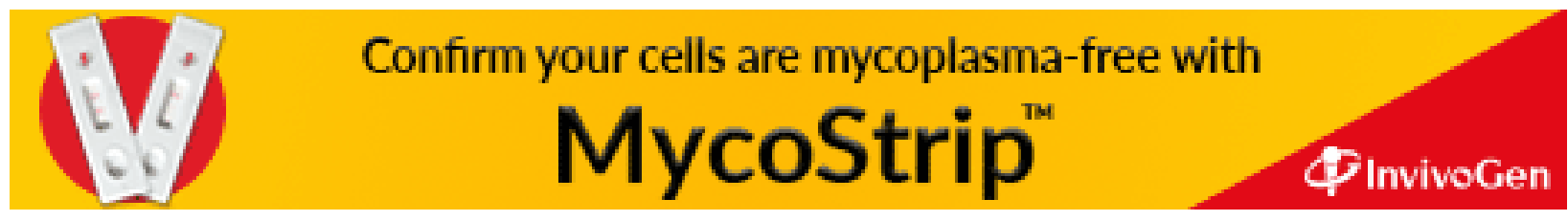

